\title{
Assessment on the Evaluation of Learning in Medical Education
}

\author{
Marta Aparecida de Lima Machado Calegari, Patricia Alves de Souza \\ Universidade do Planalto Catarinense (UNIPLAC), Lages, Brazil \\ Email: martatina9@gmail.com
}

How to cite this paper: de Lima Machado Calegari, M. A., \& de Souza, P. A. (2017). Assessment on the Evaluation of Learning in Medical Education. Creative Education, $8,935-941$.

https://doi.org/10.4236/ce.2017.86068

Received: August 31, 2015

Accepted: May 24, 2017

Published: May 27, 2017

Copyright $\odot 2017$ by authors and Scientific Research Publishing Inc. This work is licensed under the Creative Commons Attribution International License (CC BY 4.0).

http://creativecommons.org/licenses/by/4.0/ (c) (7) Open Access

\begin{abstract}
The evaluation of learning has been the subject intriguing, full of stigmas historically constructed. Sometimes (most) is seen as instrument of punishment, coercion, discipline. The nature is classified as descriptive exploratory approach with mixed quantitative and qualitative. To collect data, questionnaires were given to students and teachers from $1^{\text {st }}$ to $4^{\text {th }}$ year course and consultation with the instruments of Student Performance Evaluation (SPE). Treatment of qualitative data was by content analysis. It was observed that there are similarities between the objective and practice, teachers and students recognize the systematic evaluation used as a component in the construction of knowledge, however, is not fully understood the operationalization process of this design evaluation by the subjects involved in research, because existence of distortions in its implementation by students and teachers compromising the pedagogical dimension of assessment, for example the "standardization" of the considerations made in relation to student performance. These factors credibility in SPE by students showed decline throughout the course. However the traditional evaluation culture is still present in moments of assessment because the talks are still noticeable feeling of fear of exposing opinions. It was therefore concluded that no action needs to SPE in practice between in accordance with the theory, for example, with skills that motivate teachers to the correct implementation of the proposal. It is also necessary to make the student realize the process as responsible for the results in individual and collective performances of SPE.
\end{abstract}

\section{Keywords}

Medicine, Instruments Performance, Student

\section{Introduction}

In the face of social change, there is no more room for a decoupled from reality 
education. The fragmented knowledge is unaware of the requirements of the occupational structure. Cultural capital, in the definition of Bordieau (2005) is made up of ideas and knowledge that people use when they participate in social life.

Since the dawn of its existence, the university goes through many transformations throughout global context. Universities, interacting with society, conditioning it or being conditioned, have an important role in promoting citizenship (Trindade, 2000).

In Brazil in 2001, the Ministry of Health (MS) Ministry of Education and Culture (MEC) and the Department of Health Policy/Secretary of Higher Education established the National Program for the Encouragement of Curricular Changes in Medical Courses (PROMED), seeking greater expressiveness in the area of Health, referencing the constitutional principles of the Unified Health System (SUS). The SUS is the Brazilian health system that implemented the universal access of people, equity in care and completeness of free shares. The relationship established between health and education emerges the need to rethink the profile of the training of doctors having as parameter the National Curriculum Guidelines own graduation course (DCN) in Medicine (Brazil, 2001).

In this context, the University of Santa Catarina Plateau (UNIPLAC), is located in the municipality of Lages in the state of Santa Catarina has 158961 inhabitants. It began in 2003 the process to deploy the Medical School in the mountain region already in line with the new model. For this purpose, given what determine the DCN in Medicine, MEC and ABEM, opted for a different proposal of curriculum and teaching-pedagogical concept for the training of medical professionals, and active methodologies of Problem-Based Learning (PBL) and methodology of curriculum, replacing the traditional curriculum (Brazil, 2001).

For the formation of a general practitioner, humanist, critical and reflexive, new requirements determine the (re) construction of the curriculum model of health care courses.

The course of the operating system is regular, with an annual inflow of students through entrance exam, offering 50 places/year. The course duration is six years, comprising a workload of 9640 hours. The operating round is complete. The credits are distributed in Educational Units that make up the curricular structure of the course, totaling 640 credits.

The curricular organization is structured in Educational Units from the $1^{\text {st }}$ to the $6^{\text {th }}$ year of the course, taking as reference the life cycles in a stepwise approach in achieving the performances. As stated in the PPC course "medical competence designed the curriculum of the course expressed what the professional should know and be able to do to exercise your practice with responsibility and quality in different health-problem situations/disease and in different contexts" (UNIPLAC, 2012).

Currently, competence is understood as dialogic, integrative attributes and contexts, linking cognitive, psychomotor and affective skills. And competence is 
the synthesis of professional profile of the course studied here. By inferred value judgment, their performance cannot be observed directly, since they constitute the coordination and integration of results.

To carry out the assessment of competence, then, a variety of instruments are necessary that, interrelated, may reveal and analyze the areas of expertise involved and the multiple elements that constitute it.

To identify the evaluation practices medical education and its relationship with the conceptual principles of the Pedagogical Project of the Course that train the professionals in this area.

\section{Methodology}

This research is characterized as the nature of descriptive exploratory approach with mixed quantitative and qualitative.

The instruments used for data collection were a source of information: questionnaires administered to students and teachers, forms of student performance assessment, with student performance record in tutoring sessions, and consulting the pedagogical project of the course. They were subjected to analysis to establish a comparison between the collected results, the theoretical and methodological design PPC course and literature review.

The questionnaires were randomly distributed to teachers and students from $1^{\text {st }}$ to $4^{\text {th }}$ year of the course. 40 compounds questionnaires of 14 questions, divided into number of 10 questionnaires to students each year course were distributed. Teachers received 12 questionnaires, containing 12 specific questions relating to systematic assessment used in the course.

\section{Results and Discussion}

The evaluation system adopted in the course of UNIPLAC of medicine was developed allowing a qualitative and quantitative analysis of the teaching-learning process from two perspectives: formation, also known as a regulator, which makes possible to identify strengths and process weaknesses, in order to overcoming the identified problems; and summative, whose purpose is to define the progress of the student in the course of each of the Educational Units. The legal framework is based on the National Curriculum Guidelines for medical courses in the MEC principles, the Law of Guidelines and Bases No 9394/96, the General Regulations of UNIPLAC and PPC medical school.

The performance of the evaluated student is given concept "satisfactory" (S) or "Unsatisfactory (I) - (Opinion n.748 of 18/06/2004 - University Council CONSUNI/- Board of Education and Research - CONSEPE). As a criterion for approval, students must achieve "S" concept in all forms of assessment contained in the school year and minimum rate of $75 \%$ (seventy five percent) in the activities selected for each Educational Unit in different teaching scenarios and learning (UNIPLAC, 2013).

Of the 50 questionnaires distributed to students, 26 returned $(52 \%)-1^{\text {st }}$ year: 5 questionnaires (19\%); $2^{\text {nd }}$ year: 7 questionnaires $(27 \%) ; 3^{\text {rd }}$ year: 8 question- 
naires $(31 \%)$ and $4^{\text {th }}$ year: 6 questionnaires $(23 \%)$. In the sample, $42 \%$ were female and 58\% male. The range of age among respondents varied between 17 and 40 years. As to the 12 questionnaires distributed to teachers, 06 returned questionnaires.

How to access to the results of the evaluations, the indices show that the vast majority of students (89\%) have access through fed back by teachers, as is proposed in this evaluative mode and PPC course. Two students of the $1^{\text {st }}$ year marked more of a chance in this item, demonstrating that also have access to return via email and coordinating the course. In the perception of the students regarding the consistency of the procedures adopted by the teacher to make the SPE, $50 \%$ of students realize full consistency in the procedures used by the teacher to carry out SPE and 50\% see partial coherence.

Impressions taken from the records show that some opinions on the design of evaluation, are in the perspective of breaking culturally cemented concepts about evaluation as a mechanism of control, verification, understanding it in its formative dimension as necessary for the process construction of knowledge (Hadji; 2001), as proposed in the PPC course. However, still perceive evidence of understanding of evaluation as verification of learning as it relates to the assessment and measurement of the seized (Zabala, 1998).

On student responses on the views expressed in the performance assessment instruments and their implications on the performance of the same. It was observed that 46\%, 12 students who consider that the comments made by Professor allow fully improve their performance. However, $50 \%$ of students identic to 13 students, consider that the comments made by Professor allow partially improve your performance. As the records do not allow for improvements in student performance, there was only one manifestation, which is equivalent to $4 \%$ of the total.

In the $1^{\text {st }}$ year course for students' opinions as to consider that the comments made by Professor allow fully improve their performance, with $60 \%$ index, or 3 students. In the $2^{\text {nd }}$ year of course, the acceptance percentage as the observations made by the teacher make possible entirely improvements in student performance is $86 \%$ : 06 students, and 01 student believes that the observations made partially possible improvements in their performance.

Already in the intervening years, the view that the observations made possible in part $-3^{\text {rd }}$ year $62 \%$, equivalent to 05 students, and also 03 students or $38 \%$ of the view that the notes provide full performance improvements thereof. Already the $4^{\text {th }}$ year the highest rate, $83 \%$, or 05 students is located as the opinion that the observations made possible in part improvements in performance. It was found specifically in the $4^{\text {th }}$ year of course understand that the opinion that the observations made do not allow improvement in student performance, $17 \%$ or 01 student.

It was observed that $58 \%$ of students (15) consider fully understood the teacher's observations recorded in the Performance Evaluation. Already 38\% (10) of the students are of the opinion that the observations are partially unders- 
tandable and only $4 \%$ (01) of this group of students considered incomprehensible remarks made by Professor in Performance Evaluation.

Students of $1^{\text {st }}$ year include evaluation as an important tool to identify student achievement, group and teacher, aiming improvement. There is agreement on the responses of students when designing evaluation as a necessary resource in identifying the strengths and weaknesses enabling process regulation. After analyzing the data collected when asked about the student's understanding of the assessment was identified distinct definitions for their role in the learning process as: test, verify analysis, discussion, acknowledgement.

The students' perception on the relevance of the comments made in SPE to enable reschedule your performance. We have watched that $65 \%$ of respondents, or 17 students believe that the observations made in the Performance Assessment tool are totally relevant, $31 \%$ of students (08) considered partially relevant, with $4 \%$ or 01 student demonstration opposing the relevance of observations.

The opinions show that students conceive the evaluation as a mechanism that helps to identify weaknesses and strengths both individual and group, including here the teacher. For Hadji (2001), evaluation differs from a scientific measure, considers the act to assess how establishing correlation, clashes, enabling negotiations with a view to re-plan teaching and learning activities.

The question of student satisfaction as a form of assessment applied, 77\% of students, or 20 of these opined that like the way the assessment is applied in the course. By contrast, 23\% of students, equivalent to 6 students are dissenting opinion, being in disagreement with the evaluation method used.

What was observed in the records expressed here is that students mostly are not opposed to proposed evaluative used in the course. They understand therefore that systematic evaluation is relevant as an important learning tool to assist in developing their performance.

Being already in the course of 1 year there is a percentage of $20 \%$ (01 students) of dissatisfaction with the form of evaluation applied. However, in the $2^{\text {nd }}$ year, there is unanimous acceptance from the level of satisfaction with the form of evaluation applied.

By observing the percentage per year, it is the $4^{\text {th }}$ course year that found a higher rejection as a form of evaluation used, SPE, demonstrating the dissatisfaction of students.

Given the considerations it means that the evaluation practice throughout the course (specifically from $1^{\text {st }}$ to $4^{\text {th }}$ Year-focus of this research) has direct implications on the credibility and legitimacy of the evaluation design. That is, in accordance with notices, which is proposed as SPE assessment is partially covered, since there is mismatch between what is established and what is experienced.

Times for the peer review print the need for students to make their considerations related to the performance of other group members (teachers and students), referenced in pre-established criteria avoiding subjectivity in considerations. The development of communication skills, the exercise of receiving and making criticisms, are building blocks with the purposes of the BPA. All state- 
ments made by a student can identify the necessity of using coherent language, avoiding discouraging the other.

There is good the acceptance of the evaluation proposal in $1^{\text {st }}$ and $2^{\text {nd }}$ course year. The $3^{\text {rd }}$ and $4^{\text {th }}$ year, high rejection rate, and the students of the $4^{\text {th }}$ year do not recognize the Student Performance Assessment as learning moment. For the $3^{\text {rd }}$ and $4^{\text {th }}$ year the records of the assessments are inaccurate and are not significant to improve their performance.

According to Perrenoud (1999), for which a proposal for formative assessment becomes effective, it is necessary to invest in teacher training with discussions that assist in the understanding of curriculum and teaching and learning, without ignoring the knowledge and practices that teachers already have. Some opinions illustrate the procedures used by teachers to make the fed back, and printing these on the behavior of students.

\section{Final Considerations}

Through this study, it concluded that the design of the students have about the assessment is in line with the proposed PPC in the course. However, realization of the concept of evaluation proposal is not fully effected in practice in the form of Student Performance Evaluation. Although there are moments of approach between theory and practice, there are still conflicts that are impediments to a comprehensive evaluation. However, it was demonstrated the existence of distortions in the operation of educational goals for students and especially by teachers, compromising the pedagogical dimension of evaluation.

The systematic assessment at SPE prints change of attitude of teachers and students, different from the position that they play in traditional evaluative culture, especially teachers as mediators of the process. The evaluation process of SPE urges teachers and students to share knowledge in a process of learning from each other. However, the traditional evaluation culture is still present in moments of assessment because the talks are still noticeable feeling of fear of exposing opinion in times of self and observer and also be exposed before the appraiser. So the SPE not fully fulfills its role as the reflective considerations do not reveal the actual performance of the subjects in the process. Teachers and students, by not being faithful to his impressions of the considerations, empty the meaning of information compromising the essence of formative evaluation as reflective analysis, aimed at the student's development in cognitive, affective and psychomotor.

There was a decline in acceptance of performance evaluation in the final year course in relation to the initial years, which redirects the subject to what we call comfort zone, keeping in view the traditional summative evaluation.

Some "standardization" of the considerations made by the teacher repeating the same wording, style "copy-paste" compromise the real student evaluation was not properly operationalized the instrument, according to the conception of formative assessment.

It is necessary to make the student realize the process as responsible for the 
results in individual and collective performances of SPE. In this context, the institution, teachers and students would be in line for the SPE effectively consolidated as learning moment.

Although there on the course a group of educational support that articulates the continuing education meetings weekly, there is little participation by teachers. In this context it is up some questions for future research in seeking to understand how the training is going on. What are the reasons that lead teachers to not participate in training? Are they motivated?

To expand the search to all the years of course and in all Educational Units that make up the curriculum, to analyze whether the trends presented here remains or reversed in later years and in other settings.

Apply the same research institution with another course with the same pedagogical proposal for the purpose of comparing the results of this research on the perception of those involved in relation to home care assessment tools.

One of the formative evaluations to the characteristics is to use the results as a starting point for re-planning of actions by both the teacher and the student. Therefore the results of evaluations made by the students must return to them through a row fed back action plans prepared by the teacher, aiming to work out the difficulties diagnosed and there owns.

\section{References}

Bordieau, P. (2005). Cultural Capital, School and Social Space. Siglo XXI Editors, s.a. de c.v. Compilation and Translation Izabel Jimenez.

Brazil (2001). Ministry of Health / Ministry of Education - Secretariat of Health Policies / Secretariat Higher Education-Project to Encourage Curricular Changes in the Course of Medicine. http://portal.mec.gov.br/sesu/arquivos/pdf/inc.pdf

Hadji, C. (2001). Demystified Assessment. Porto Alegre: Artmed.

Perrenoud, P. (1993). Pedagogical Practices: Teaching Profession and Training: Sociological Perspectives. Lisbon: Don Quixote Publications.

Trindade, H. (2000). Knowledge and Power: The Dilemmas of the Brazilian University. http://www.scielo.br/pdf/ea/v14n40/v14n40a13.pdf

UNIPLAC (2012). University of Planalto Catarinsne. Statute of the University.

UNIPLAC (2013). Proposal for a Modification of the Opinion CONSUNI / CONSEPE n. 1325, Dated 04/28/2005, Which Regulates the Evaluation of the Teaching Learning Process of the Medical Course-Regulation.

Zabala, A. (1998). The Educational Practice. Porto Alegre: Artmed. 
Submit or recommend next manuscript to SCIRP and we will provide best service for you:

Accepting pre-submission inquiries through Email, Facebook, LinkedIn, Twitter, etc. A wide selection of journals (inclusive of 9 subjects, more than 200 journals)

Providing 24-hour high-quality service

User-friendly online submission system

Fair and swift peer-review system

Efficient typesetting and proofreading procedure

Display of the result of downloads and visits, as well as the number of cited articles Maximum dissemination of your research work

Submit your manuscript at: http://papersubmission.scirp.org/

Or contact ce@scirp.org 